\title{
Interaction of carboxymethylchitosan and heavy metals in cement media
}

Department of Chemistry and Soil Sciences, University of Navarra, c/ Irunlarrea, 1, 31.080, Pamplona, Spain

\begin{abstract}
The performance of an etherified chitosan, carboxymethyl chitosan $(\mathrm{CMCH})$, when added to cement mortars doped with heavy metals, was assessed. In the presence of heavy metals $(\mathrm{Cr}, \mathrm{Pb}, \mathrm{Zn})$ strong modifications of the fresh-state properties were evaluated. The addition of the polymer was seen to be useful in minimising some of these modifications, as those related to the setting time. A competitive mechanism for adsorption between the oxoanionic form of the metals and the carboxylate groups of the chitosan derivative was established. Studies on the metal chelating ability of the polymer and leaching from the hardened specimens showed scarce complexation under alkaline conditions, pointing to physical entrapment based on metal adsorption. However, significant chelation of metals was proved at near-neutral $\mathrm{pH}$, suggesting the potential usefulness of the polymer as a agent for removing heavy metals from polluted waters and subsequently immobilizing them in cement mortars. Leaching tests carried out on polymer-metal complex-bearing samples showed a significant reduction in the amount of released $\mathrm{Pb}$ and $\mathrm{Zn}$.
\end{abstract}

\section{* Corresponding author:}

Dr. José Ignacio Álvarez Galindo

Departamento de Química y Edafología, Universidad de Navarra

C/ Irunlarrea, 1, 31.080 Pamplona (Navarra), Spain

Phone: 34948425600

Fax: 34948425649

e-mail: jalvarez@unav.es

\section{Keywords}

Fresh-state properties, polymer-cement composites, complexation, heavy metals, adsorption, zeta potential, leaching 


\section{Introduction}

Cement mortars have usually been used to block the pernicious effects of hazardous wastes (e.g. heavy metals) by immobilizing them [1,2]. As a result of the chemical properties of the cement, the solidification/stabilization $(\mathrm{S} / \mathrm{S})$ processes may involve both physical entrapment (adsorption) and/or chemical binding (complexation) of the contaminant to the cement matrix. It has been reported that $\mathrm{Pb}, \mathrm{Cr}$ and $\mathrm{Zn}$ compounds modify the hydration and rheological properties of the cement owing to their interaction with different cement phases $[3,4]$. The reported changes in fresh-state properties of the cement mortars can be detrimental to their usefulness and applicability. In addition, their long-term stability can be jeopardized, thus increasing the leaching of heavy metals.

Some polymeric additives can be added to cement mortars in order to modify their properties, improving their heavy metal retention ability and minimizing, or even overcoming, the negative effect of those metals in fresh-state properties [4]. Other admixtures such as sugar derivatives have been shown to add flexibility to the handling of cement-treated metal waste, by modifying the fresh-state properties of the cement mortar [5]. In a previous study, chitosan molecules have been reported to complex several heavy metals efficiently [6]. However, as a consequence of the insolubility of the chitosan at the alkaline $\mathrm{pH}$ of the cement matrices, its incorporation in the cement mortars led to slight changes in the fresh-state mixtures. In this paper, the role of a water-soluble carboxymethylchitosan chitosan derivative $(\mathrm{CMCH})$ is addressed. The introduction of some functional hydrophilic groups (carboxylic) in the polymer chain leads to a solubility increase at alkaline $\mathrm{pH}$, justifying of the potential of this derivative with a view to its use in cement systems.

The aim of the current research is to investigate the effects of the addition of $\mathrm{CMCH}$ on fresh-state properties and leachability for heavy metal doped-cement mortars. The selected metals were $\mathrm{Pb}(\mathrm{II}), \mathrm{Cr}(\mathrm{VI})$ and $\mathrm{Zn}(\mathrm{II})$, as they have been identified as priority metallic pollutants and they have been shown to have an influence on the fresh-state properties of cement-based mortars [5, 7-9]. The polymer's ability to chelate heavy metals as a way of removing them from waste waters and subsequently retaining them in cement mortars was also studied. 


\section{Experimental}

\subsection{MATERIALS}

An ordinary Portland cement (OPC) (CEM II 32,5 N, supplied by Portland S.A. Olazagutía, Spain) and a siliceous aggregate were used to prepare the mortars. Material characterization and grain size distribution of the aggregate are reported elsewhere [10].

The tested polymer was a carboxymethylchitosan derivative, which was purchased from Heppe Medical (Ref. 40002). The characterization of the $\mathrm{CMCH}$ polymer showed a molecular weight of $51 \mathrm{KDa}$ and a deacetylation degree of $99 \%$. These data were obtained according to methods based on viscosity measurements and first derivative ultraviolet spectrophotometry, respectively [11,12]. The derivative is a N,Ocarboxymethylchitosan, with a degree of substitution (DS) of 0.9 according to the data from the supplier. DS can be determined by the molar ratio of carboxymethyl acid groups to monosaccharide units, as follows: $\mathrm{DS}_{\mathrm{abs}}=\mathrm{mol}$ of $-\mathrm{CH}_{2} \mathrm{COOH}$ groups $/ \mathrm{mol}$ of monosaccharide unit [13]. In Fig. 1, FTIR results of the polymer show the occurrence of an intense band at $1588 \mathrm{~cm}^{-1}$ and a moderate band at $1411 \mathrm{~cm}^{-1}$, which, in accordance with previously published results, were attributed to the symmetric and asymmetric axial deformations of COO, respectively $[14,15]$. These facts confirmed the introduction of the carboxymethyl groups to the polymer chain.

When necessary, the heavy metal load was made from $\mathrm{Zn}\left(\mathrm{NO}_{3}\right)_{2}, \mathrm{~Pb}\left(\mathrm{NO}_{3}\right)_{2}$ (Merck, Darmstadt, Germany) and $\mathrm{K}_{2} \mathrm{Cr}_{2} \mathrm{O}_{7}$ (Panreac, Barcelona, Spain).

\subsection{MORTAR PREPARATION}

Cement, aggregate, additive and heavy metal (these last compounds only when necessary) were blended for 5 minutes with a solid mixer (Lleal S.A.). Then, water was added and mixed for 90s at low speed, in a Proeti mixer. Mortars settled for 10 minutes before the tests. The binder:aggregate ratio was 1:3 by weight. In order to compare the effect of the addition of the polymer to the mortar, all the samples were prepared with the same water:cement ratio, 0.55 . The additive was added at $0.4 \%$ of the cement weight while the heavy metal was incorporated in $1 \%$ with respect to cement. 


\subsection{TESTS}

\subsubsection{Fresh state properties of the mortars}

The following standardised tests were used: the flow table test in order to measure consistency [16], water retention capacity [17] and setting time [18].,

\subsubsection{Cement Solutions}

Specific mixtures of cement, heavy metal, water and additive were prepared to assess the zeta potential. Following the method proposed by Zhang et al. [19, 20] and assayed previously [21], solutions with different concentrations of $\mathrm{CMCH}$ (from 0.025 to 0.60 wt.\%) were prepared. Cement was added with a solute/liquid ratio of 0.0025 and heavy metal ( $\mathrm{Zn}, \mathrm{Pb}$ or $\mathrm{Cr}$ ) was added at a $1 \%$ metal/cement ratio. After 20 minutes of stirring, the mixtures were separated by centrifuging, and the supernatants were analyzed using a Zeta Potential Analyzer ZETA PLUS (Brookhaven Instruments Corporation, New York, U.S.A.). Reported values are the average of twenty measurements.

For particle size distribution (PSD) measurements, $20 \mathrm{~g}$ of cement were added to $100 \mathrm{~g}$ of solutions with different amounts of $\mathrm{CMCH}$ in water, the resulting $\mathrm{CMCH} /$ cement ratios ranging from $0 \%$ to $1 \%$. A $1 \%$ (metal/cement) load of $\mathrm{Zn}, \mathrm{Pb}$ or $\mathrm{Cr}$ was, in each case, added to the solutions. PSD of these samples was determined using a Mastersizer (Malvern Instruments, U.K.).

Optical microscopy and TEM examinations were carried out in order to assess the above-mentioned measurements. For optical microscopy, the solutions prepared were similar to those of PSD ( $20 \mathrm{~g}$ of cement in $100 \mathrm{~g}$ of solution) with $\mathrm{CMCH} /$ cement ratio of 1\%. The images were taken with an optical Olympus $\mathrm{CH} 40$ microscope, with Color view- soft imaging systems camera. TEM images were obtained from a solution of $5 \mathrm{~g} / \mathrm{L}$ of cement with a $1 \%$ of $\mathrm{CMCH}$. One drop of this suspension was disposed on a copper grid and subsequent measurements were carried out with and without contrast (phosphotungstic acid) in a LIBRA 120 energy-filtering TEM (Zeiss) operated at 80 $\mathrm{KV}$. 


\subsubsection{Chelating behaviour in solutions}

The carboxymethylchitosan derivative and metal solutions were dissolved at different pHs $\left(13,11,8.25\right.$ and 7). Either $0.1 \mathrm{M} \mathrm{HAc} / \mathrm{NaAc}$ or $0.1 \mathrm{M} \mathrm{Na}_{2} \mathrm{HPO}_{4} / \mathrm{H}_{3} \mathrm{PO}_{4}$ were used for $\mathrm{pH}=7.00$ whereas $0.1 \mathrm{M} \mathrm{NH}_{4} \mathrm{Cl} / \mathrm{NH}_{3}$ buffer solutions were prepared for $\mathrm{pH}$ 8.25. Certipur standard solutions containing $1000 \mathrm{ppm}$ of the heavy metals $\mathrm{Zn}(\mathrm{II})\left(\mathrm{Zn}\left(\mathrm{NO}_{3}\right)_{2}\right.$ in $\left.\mathrm{HNO}_{3} 2-3 \%\right)$ and $\mathrm{Pb}(\mathrm{II})\left(\mathrm{Pb}\left(\mathrm{NO}_{3}\right)_{2}\right.$ in $\left.\mathrm{HNO}_{3} 2-3 \%\right)$ and $\mathrm{Cr}(\mathrm{VI})\left(\mathrm{K}_{2} \mathrm{CrO}_{4}\right.$ in $\left.\mathrm{H}_{2} \mathrm{O}\right)$ were purchased from Merck (Darmstadt, Germany).

Voltammetric measurements were performed with a Metrohm 746 VA Trace Analyzer coupled with a 747 VA Stand. A three-electrode arrangement consisting of a glassy carbon counter electrode, an $\mathrm{Ag} / \mathrm{AgCl} / \mathrm{KCl} 3 \mathrm{M}$ reference electrode and mercury electrode were used. All the complexes were proved to be formed quasiinstantaneously, so that a minimum conditioning time $(60 \mathrm{~s})$ was allowed after every spike of metal. A known amount of ligand was placed in the electrochemical cell and then increasing amounts of $\mathrm{Zn}$ and $\mathrm{Pb}$, respectively, were spiked on the different solutions.

Metals were accumulated onto the mercury electrode by applying a sufficiently negative potential (ca. $300 \mathrm{mV}$ with respect to the respective anodic stripping peaks) for $60 \mathrm{~s}$, followed by a resting time of $30 \mathrm{~s}$. Measurements were made on the differential pulse mode (DPV) with a pulse amplitude of $50 \mathrm{mV}$ throughout and a scan rate of $20 \mathrm{mV} \mathrm{s}^{-1}$. Dynamic Light Scattering measurements were done by means of a Dynapro (model $\mathrm{MS} / \mathrm{X}$ ) photonic correlation spectrometer equipped with a 248 multi-tau correlation channel and a Peltier thermostat unit. Laser source wavelength was $825.2 \mathrm{~nm}$. Detector was orthogonal to the source and autocorrelation intensity software was included in the Dynamics ${ }^{\mathrm{TM}}$ package. Cells of $1 \mathrm{~cm}$ pathway were employed and hydrodynamic radii were calculated from diffusion coefficients according to the Stokes-Einstein equation.

\subsubsection{Leaching tests of heavy metals in $\mathrm{CMCH}$-modified cement mortars}

Fresh mixtures prepared according to section 2.2. were afterwards moulded and cured for 28 days [22]. Cylindrical test pieces of $40 \mathrm{~mm} \times 37 \mathrm{~mm}$ were placed in sealable 110 mm x $110 \mathrm{~mm}$ x $110 \mathrm{~mm}$ methacrylate tanks. 
The determination of the leaching of inorganic components of mortars was carried out following the Tank Test [23]. This test involves placing a complete sample in a leaching fluid (demineralized neutral $\mathrm{pH}$ water) and replenishing the leachate at specified times. After the period indicated, all the eluate was drained off and filtered with a nylon membrane of $0.45 \mu \mathrm{m}$ of pore size (CHMLAB Group, Barcelona). A fixed volume of $10 \mathrm{~mL}$ of each sample was stored with nitric acid sub-boiling for further analysis of the concentration of the leached components. Afterwards, the tank was filled again with the same quantity of water (1L) and the procedure was repeated. The eluates were collected at eight different times $(0.25,1,2.25,4,9,16,36$ and 64 days $)$.

The concentration of the leached $\mathrm{Cr}, \mathrm{Zn}$ and $\mathrm{Pb}$ was measured by atomic absorption spectrometry (Perkin-Elmer AAnalyst 800).

Chromium measurements were performed at $357.9 \mathrm{~nm}$, using a hollow cathode lamp operated at $25 \mathrm{~mA}$ and bandwidths of $0.7 \mathrm{~nm}$. An air/acetylene flame with a 10.0/2.0 $\mathrm{mL} \min ^{-1}$ flow ratio was used.

Transversely-heated graphite tubes with end caps supplied by Perkin-Elmer were used for zinc and lead determinations. Integrated absorbance peak areas were measured by using single element hollow lamps. Argon was used as the inert gas, the flow rate being $250 \mathrm{~mL} \mathrm{~min}{ }^{-1}$ during all stages except atomisation, when the flow was stopped exclusively for lead. The instrumental settings and temperature programme of the spectrometer were optimised as summarized in Table 1.

Pore structure of the hardened specimens was assessed by mercury intrusion porosimetry. A Micromeritics AutoPore IV 9500 with a range of pressure between 0.0015 and $207 \mathrm{MPa}$ was used.

Additionally, in order to assess the effectiveness of a previous complexation, the leachability of a series of mortars prepared with a previous reaction of the metal and polymer in solution was studied. These mortars were obtained as follows: solutions of $1 \%$ (metal/cement ratio) of each metal ( $\mathrm{Zn}$ and $\mathrm{Pb}$, in this case) were prepared and the $\mathrm{pH}$ was adjusted to 7.00 or 8.25 with a solution of $\mathrm{NH}_{4} \mathrm{Cl} / \mathrm{NH}_{3}$. The criterion for $\mathrm{pH}$ selection was to set a $\mathrm{pH}$ value as high as possible (keeping, to a certain extent, similarity to the alkaline matrix of the cement) but allowing a certain degree of complexation to take place. This fact depends on the metal speciation, i.e. the chemical form of the heavy metal that can be complexed. As $\mathrm{CMCH}$ at neutral or alkaline $\mathrm{pH}$ deprotonates giving rise to carboxylate groups, cationic forms of heavy metal would be able to be retained by the polymer. In this sense, $\mathrm{pH} 7$ turns out to be the limit for the 
appearance of $\mathrm{Pb}^{2+}$, as from this $\mathrm{pH}$ onwards it starts to precipitate as $\mathrm{Pb}(\mathrm{OH})_{2}$ and cannot be chelated. On the other hand, $\mathrm{pH} 8.25$ is the limit for the $\mathrm{Zn}^{2+}$ presence.

Then, the $\mathrm{CMCH}$ powder was added to the solutions. This mixture was kept under magnetic agitation for 24 hours to guarantee the dissolution and the complexation of the components. The resulting solution was added to the solid components of the mortar (as mixing water) and mixed as indicated in section 2.2. Leaching tests were also carried out as described above.

\section{Results and Discussion}

\subsection{Fresh-state behaviour of CMCH-modified mortars}

Figure 2 shows the slump results of cement mortars modified by loading the target heavy metals with and without the addition of $\mathrm{CMCH}$. The addition of either $\mathrm{Pb}$ or $\mathrm{Cr}$ caused, if any, very little changes in the slump (a fluidity reduction of around $6 \%$ for $\mathrm{Cr}$ and around 3\% of flowability increase when $\mathrm{Pb}$ was added by comparison with the plain cement mortar). Nonetheless, the addition of $\mathrm{Zn}$ was highly detrimental for the consistency behaviour of the mortars, because it gave rise to a notably heterogeneous mixture, which in fact was disaggregated, hindering the right measurement of the slump.

The addition of $\mathrm{CMCH}$ involved a strong fluidity reduction for the plain cement mortar (48\% reduction in fluidity). The heavy metal bearing mortars also showed a slump reduction, but to a lesser extent than the plain mortar $(4.5 \%$ for $\mathrm{Cr}$-loaded mortar and 9\% for $\mathrm{Pb}$-loaded mortar). It is thus evident that the presence of the heavy metals thwarted the effect of the polymer addition on the consistency of the fresh mixture.

From the results of the water retention ability (Fig. 3), it can be concluded that chromium and lead did not modify this property when added to a plain cement mortar. However, the zinc addition clearly increased the retained water (almost 20\% increase compared to the plain mortar).

When $\mathrm{CMCH}$ was added to the plain mortar, the water retention capability of the fresh mixture was increased by $10 \%$. No significant changes were found when $\mathrm{CMCH}$ was incorporated in heavy metal loaded mortars. Once again, the presence of the metals spoilt the polymer effect. 
Measurements of the setting time showed the most important changes in fresh-state $45 \%$ in comparison with the plain mortar, whereas the addition of lead caused a delay in the setting time of 75 minutes. Owing to the aforementioned effect of the $\mathrm{Zn}$ on the mortar's consistency, setting time results could not be properly determined in the presence of this metal, so the results are not shown.

The effect of the CMCH polymer on these samples was noteworthy: it caused a strong decrease in the setting time in plain cement mortars (the setting process was accelerated by $65 \%$ ). On the other hand, $\mathrm{CMCH}$ lessened the effect of heavy metal addition in the mortar setting time either by delaying the setting time for chromium-samples or by reducing it for lead-samples. In the latter case, the setting time was reduced by as much as 120 minutes. These experimental findings suggest the effectiveness of $\mathrm{CMCH}$ addition in overcoming the strong modifications in setting time produced by the incorporation of either $\mathrm{Cr}$ or $\mathrm{Pb}$ in cement-based mortars. Therefore, this experimental evidence takes on practical relevance for the handling of metal-bearing cement mortars.

\subsection{Cement Solutions}

The previous results prompted us to make zeta potential measurements that provide information on the net-surface charge for cement particles in the cement suspensions. Figure 5 shows that the presence of the polymer, which, at such an alkaline $\mathrm{pH}$, would be a negatively charged polyelectrolyte owing to its functional carboxylate groups, shifts the zeta potential values of the cement particle surfaces towards more negative figures.

This implies an interaction between the polymer and the positively charged cement particles, giving rise to adsorption on the surface of the particles. Figure 6a depicts simulation of the adsorption of carboxylate groups of the $\mathrm{CMCH}$ onto the cement surface. This finding is supported by previous work reporting adsorption onto cement particle surfaces for carboxylate substituted polymers [24, 25]. The adsorbed polymer molecules could then link different cement particles (Fig. 6b) through the multiple carboxylate moieties, giving rise to large agglomerates of cement particles and, therefore, to a fluidity reduction as proved by the slump reduction. 
However, when negative ions were added (chromate, $\mathrm{CrO}_{4}{ }^{2-}$ ), they might compete with particles, leading to an increase in "free" polymer molecules. Since $\mathrm{CrO}_{4}{ }^{2-}$ ions might be adsorbed on the cement particles, zeta potential values were expected to remain negative, as Figure 5 confirms: when $0 \%$ of polymer was incorporated, zeta potential turned out to be negative as a result of the adsorption of chromate ions on the cement particles. In the presence of increasing polymer amounts, zeta potential values followed a similar trend to that of the metal-free samples.

It is noteworthy that zeta potential measurements for $\mathrm{Zn}$ and $\mathrm{Cr}$ follow the same pattern. This is a confirmation that most $\mathrm{Zn}$ is, under the alkaline conditions of the solution, present in the anionic form (i.e. $\mathrm{ZnO}_{2}{ }^{2-}$ ) and its competitive adsorption onto the cement particles yields a flaky consistency to the metal-loaded cement. This preference for adsorption onto the cement has previously been described elsewhere [26], although the authors claimed $\mathrm{Zn}$ to be in the cationic form linked in some way to the silicates of the cement phases. From the experiments carried out in this research and within the experimental limits of the present study, we conclude that $\mathrm{Zn}$ is rather acting in the anionic form and it competes with $\mathrm{CMCH}$ for the cement particles (Fig. 6c). This competition for the available binding sites on the cement particles justifies the attenuation of the effect of the $\mathrm{CMCH}$ in fresh-state properties observed in the presence of the assayed heavy metals.

Figure 7a shows PSD in cement solutions with different amounts of $\mathrm{CMCH}$. The addition of $\mathrm{CMCH}$ gave rise to a flocculant effect that can be observed through the growing quantity of large agglomerates ranging between 250 and $450 \mu \mathrm{m}$ as a function of the polymer dosage. As explained above, this effect arose as a result of the linking between polymer molecules and cement particles. The negatively charged functional groups of the polymer molecules, acting as anchoring groups, can be adsorbed onto positively charged cement particles (such as ettringite) causing a negative measurement of the surface potential in the compact Stern layer [27]. The formation of the agglomerates was evidenced by the optical microscopy and TEM observations of the cement solutions (Fig. 8a and Fig. 9, respectively). Large agglomerates of cement particles can be observed in these photographs, confirming the previous assumptions on the action mechanism of the polymer.

However, the addition of a $1 \mathrm{wt} . \%$ of lead, zinc and chromium exerted an influence on the performance of the polymer, decreasing the amount of large agglomerates of cement 
particles, as exemplified in Fig. $7 b$ (in the case of $\mathrm{Pb}$ ). This behaviour is in agreement competitive blockage of the binding sites on the cement particles, thus preventing some polymer molecules from adsorbing on the surface of these particles. Accordingly, the size of the agglomerates was reduced. The competition between heavy metals and $\mathrm{CMCH}$ for binding on cement particles rendered the flocculation less marked. Optical microscopy photographs allowed us to see a lower degree of flocculation between cement particles when different heavy metals were added compared to the samples without heavy metals (Fig. 8b and Fig. 8c).

Further experiments were set up in order to see whether the adsorption pattern prevails over any other mechanism such as complexation. The distinct electrochemical responses of metals in the presence of several previously fixed concentrations of $\mathrm{CMCH}(0.05$, $0.1,0.5$ and $1 \mu \mathrm{M}$ ) were monitored and served as indicators of the occurrence of a complexation pattern [6]. When the assayed $\mathrm{pH}$ was strongly alkaline ( $\mathrm{pH} 11$ to 13 , resembling the cement media), results showed that complexation proceeded to a very limited extent owing to the proportional scarce ratio of metals in their original cationic form.

These studies were also performed in less alkaline media or even in neutral solutions, in order to check if the assayed $\mathrm{CMCH}$ polymer would be of value in chelating heavy metals from slightly alkaline or neutral waste waters, so that they could afterwards be incorporated and immobilized into a cement mortar. Besides, this research would be interesting in order to explore a potential use of $\mathrm{CMCH}$ as admixture for cement with near-neutral $\mathrm{pH}$, such as some phosphate-modified calcium aluminate cement [28]. The marked influence exerted by the different $\mathrm{CMCH}$ assayed concentrations on the electrochemical response of the metal matched a typical complexing behaviour at $\mathrm{pH}$ 7.00 and $\mathrm{pH}$ 8.25. Maximum chelating effect (up to $12 \mathrm{~mol}$ of metal per MW of the $\mathrm{CMCH})$ was obtained for the minimum polymer assayed concentration $(0.05 \mu \mathrm{M})$. This chelation ability decreased as the $\mathrm{CMCH}$ concentration was increased: complexation was reduced by half for a $1 \mu \mathrm{M} \mathrm{CMCH}$ concentration.

This behaviour can be ascribed to intertwining of polymer chains among themselves when in relatively high concentrations leaving less binding positions available for the metals. At lower $\mathrm{CMCH}$ concentrations, metals could be allocated in an interlayer arrangement so that an overall larger stoichiometry results. 
Dynamic Light Scattering studies have been devised as to support this explanation. The aim of the experiments was to check whether any substantial difference in either particle size or diffusion coefficient could be found for solutions containing the metal-CMCH complex with respect to a blank solution. The solution containing just the $\mathrm{CMCH}$ polymer gave rise to a scatter pattern in which a polymer agglomerate was detected with a theoretically estimated hydrodynamic radius of $0.126 \mathrm{~nm}$ and a diffusion coefficient value of $1.94 \cdot 10^{-5} \mathrm{~cm}^{2} \mathrm{~s}^{-1}$. The same solution with an excess of metal ( $\mathrm{Zn}$ as a model) showed a different scattering profile in which a signal responsible for the $99.8 \%$ of the polymer agglomerate mass has a larger radius $(1.107 \mathrm{~nm})$ and a significantly decreased diffusion coefficient $\left(2.22 \cdot 10^{-6} \mathrm{~cm}^{2} \mathrm{~s}^{-1}\right)$. This finding supports the hypothesis of a foldedlike structure being formed between the $\mathrm{CMCH}$ and $\mathrm{Zn}$ $[29,30]$.

These results, showing complexation of the expected cationic form of either $\mathrm{Zn}$ (II) or $\mathrm{Pb}$ (II) by the polymer, allowed us to explore the leachability of these metals once they have been complexed by the polymer either at $\mathrm{pH} 7.00$ or at $\mathrm{pH} 8.25$ and incorporated into cement mortars, as described below. This study did not include $\mathrm{Cr}(\mathrm{VI})$, due to the fact that it remained as chromate.

\subsection{Leaching Tests of Heavy Metals in CMCH-Modified Cement Mortars}

Real specimens of cement mortars aged for 56 days were subjected to leaching tests, in order to assess the effectiveness of the $\mathrm{CMCH}$ as a metal retainer. However, it is necessary to state the experimental limits of the study, because it was addressed only in mortars with one water/cement ratio (0.55). Experimental results showed that the presence of heavy metals in the leachate increased when $\mathrm{CMCH}$ was added to the mortar. The accumulated values of the eluates up to testing day 64 showed that $\mathrm{CMCH}-$ free mortars leached 3778, 37 and $7 \mathrm{mg} \mathrm{m}^{-2}$ (mass of metal/test-probe surface area ratio) of $\mathrm{Cr}, \mathrm{Pb}$ and $\mathrm{Zn}$, respectively, whereas 5709,47 and $11 \mathrm{mg} \mathrm{m}^{-2}$ of those metals were released in CMC-modified mortars. These results are in agreement with previous data reporting great immobilization in hydrated cementitious matrices for $\mathrm{Pb}$ and $\mathrm{Zn}$, ranging from 99.82 to $99.99 \%$. Cr is an exception and it has been reported to be immobilized in lower degree (from 85.97 to $93.33 \%$ ) [31]. Owing to the large retention ability of cement matrices, the released amounts of both $\mathrm{Pb}$ and $\mathrm{Zn}$ were well below the upper limit of the regulatory norm (400 and $800 \mathrm{mg} \mathrm{m}^{-2}$, respectively) [32], as it has been also 
reported in a previous work [33]. However, chromium exceeded the top value indicated complexation phenomena at high alkaline $\mathrm{pH}$ between $\mathrm{CMCH}$ and the metals. The mechanism of the metal retention into the mortar matrix turns out to be largely a physical entrapment (adsorption), as proved by the experimental measurements (section 3.2.). The decrease of the available adsorption sites for the metal contributed to the increased metal release. Besides, $\mathrm{CMCH}$ was seen strongly to reduce the fluidity of the mortar as well as its degree of compactness in the fresh-state. As a consequence, larger porosity values were measured for the hardened material also contributing to the release of heavy metals in a higher ratio. Mercury intrusion porosimetry measurements showed a net porosity increase of hardened mortars prepared with $\mathrm{CMCH}$-modified cement, specially for the large-size pores (Figure 10). Further tests with a range of different water/cement ratios will be necessary in order to minimize the final porosity of the hardened mortar to assess the validity of the $\mathrm{CMCH}$ addition comprehensively in terms of leaching.

However, when $\mathrm{Zn}$ and $\mathrm{Pb}$ were previously sequestrated by the polymer from solutions of $\mathrm{pH}$ values of 7 and 8.25 and subsequently incorporated in the cement mortars, the leachability of these metals was improved when compared with results obtained for the polymer-absent metal-bearing cement mortar. Fresh-state properties of the cement mortars prepared in this way did not show any significant alteration with respect to the data obtained from mortars prepared by powdered $\mathrm{CMCH}$ addition, as discussed in section 3.1. Figure 11 shows the accumulated leachability results for $\mathrm{Pb}$ and $\mathrm{Zn}$, in: (a) polymer-absent cement mortars; (b) mortars modified by the addition of $\mathrm{CMCH}$ in powder (as reported above); and in mortars in which metals were incorporated in their polymer-complexed form both at pH 7.00 (c) and 8.25 (d).

The leachability of lead was clearly reduced when considering the accumulated results after 54 hours ( 2.25 days) if the metal was incorporated in the polymer-complex form. Compared to the immobilizing ability of the plain cement mortar, the addition of the $\mathrm{CMCH}-\mathrm{Pb}$ complex reduced the $\mathrm{Pb}$ leachability in a $28.6 \%(\mathrm{pH} 7.00)$ or in a $17 \%(\mathrm{pH}$ 8.25). The differential between the polymer-free cement and the $\mathrm{CMCH}-\mathrm{Pb}$ complex underwent a slight reduction at day 9. The $\mathrm{CMCH}-\mathrm{Pb}$ complex within the cement matrix remained stable from day 16 onwards. In Figure 11, an increasing trend for lead leaching from plain cement can be observed, while a plateau has already been reached at day 16 for the lead leaching from the polymer-metal complex cement. As an 
evidence, 36-day measurements of the lead released from the $\mathrm{pH} 7.00$ polymer-complex cement showed a reduction of ca. 10\% in the leachate compared to the plain cement mortar, thus showing the effectiveness of the complexation process with the $\mathrm{CMCH}$ polymer.

As far as the leachability of $\mathrm{Zn}$ is concerned, encouraging leaching values were obtained for samples prepared from $\mathrm{pH} 8.25 \mathrm{CMCH}-\mathrm{Zn}$ solutions. Day-64 results showed an $18.5 \%$ reduction of the $\mathrm{Zn}$ released in comparison with the plain cement mortar, thus revealing the benefits of using $\mathrm{CMCH}$ for chelating heavy metals and their subsequent treatment by cement-based $\mathrm{S} / \mathrm{S}$.

Differences observed between $\mathrm{Zn}$ and $\mathrm{Pb}$ as a function of the $\mathrm{pH}$ in which the chelation took place may be related to (i) the degree of ionization of the carboxylic functionalities in the polymer chain and (ii) the relative concentration of the metal species. In fact, these two factors are dependent on the $\mathrm{pH}$ of the solution: a higher $\mathrm{pH}$ value results in a higher ratio of ionized carboxylic groups, i.e. carboxylates, which are able to chelate cationic forms of the metals. On the other hand, $\mathrm{pH}$ exerts - at the same time - a strong influence over the speciation of the metals. At $\mathrm{pH} \mathrm{7,} \mathrm{the} \mathrm{majority} \mathrm{of} \mathrm{the} \mathrm{Zn}$ appears as $\mathrm{Zn}^{2+}$, while at $\mathrm{pH} 8$ small percentages of $\mathrm{Zn}(\mathrm{OH})^{+}$and $\mathrm{Zn}(\mathrm{OH})_{2}$ have also been reported [34]. This last species of $\mathrm{Zn}$ cannot be complexed by the carboxylate groups of the polymer. In the case of lead, the higher precipitation of $\mathrm{Pb}(\mathrm{OH})_{2}$ from $\mathrm{pH} 7$ onwards hinders its complexation and removal from the solution. Therefore, the amount of lead released turned out to be larger from samples prepared with polymer-metal complex at $\mathrm{pH} 8.25$, because, although the number of chelating groups of the polymer was higher, the concentration of the cationic form $\mathrm{Pb}^{2+}$ able to be chelated was as a matter of fact lower. This trend was inverted for $\mathrm{Zn}$ : the higher concentration of the cationic form $\mathrm{Zn}^{2+}$ in comparison with $\mathrm{Pb}^{2+}$ at $\mathrm{pH} 8.25$, together with a large number of carboxylate groups of the polymer, resulted in a greater complexation of the $\mathrm{Zn}$, improving its immobilization in cement mortars.

The release of $\mathrm{Pb}$ and $\mathrm{Zn}$, at the assayed concentrations of heavy metals (1\% metal/cement) - previously complexed or not -, is within the limits of the regulation [32]. As previously explained, this fact is due to the large metal retention ability of hydrated cement matrices. However, these experimental findings open a route for larger improvements in metal retention by studying the most suitable parameter involved (optimum $\mathrm{pH}$ for complexation, larger metal load and even different polymer concentrations). 


\section{Conclusions}

Addition of $\mathrm{CMCH}$ to the cement mortars caused significant changes in the fresh-state properties of the mortars: fluidity decrease and setting time reduction. Incorporation of target heavy metals $(\mathrm{Zn}, \mathrm{Cr}$ or $\mathrm{Pb})$ hindered the effect of the polymer. Strong modifications in setting time caused by the presence of either $\mathrm{Cr}$ or $\mathrm{Pb}$ may be overcome by the use of $\mathrm{CMCH}$.

Both the polymer through its anchoring groups (carboxylate functionalities) and the oxoanionic form of the target metals have been proved to adsorb onto positively charged cement particles. In the case of the polymer, this adsorption was responsible for the flocculation and setting time reduction. A competitive mechanism between the polymer and the heavy metals has been proposed in order to explain the reduced effect of the polymer when metals were included.

Studies on the chelating role of the polymer towards heavy metals showed that when the assayed pHs resembled cement media (alkaline $\mathrm{pH}$ from 11 to 13), complexation proceeded to a very limited extent owing to the proportional scarce ratio of metals in their original cationic form, pointing to the physical entrapment as the main mechanism of immobilizing heavy metals in $\mathrm{CMCH}$ polymer-cement mortars. Studies focusing on the ability of the $\mathrm{CMCH}$ in sequestrating metals from polluted waste waters with slightly alkaline o near-neutral pHs showed real complexation (up to $12 \mathrm{~mol}$ of metal per $\mathrm{MW}$ of the $\mathrm{CMCH}$ which was obtained at low polymer concentrations).

Leachability of metals from powdered $\mathrm{CMCH}$-containing cement mortars increased with respect to plain cement mortars, in accordance with the observed higher porosity of the hardened specimens. On the other hand, an improvement in the immobilization of $\mathrm{Pb}$ and $\mathrm{Zn}$ in the cementitious matrices was achieved by previously complexing the metals in near-neutral $\mathrm{pH}$ solutions by $\mathrm{CMCH}$. After 64 days, the cumulative amount of $\mathrm{Pb}$ released decreased by $10 \%$ with respect to plain cement, whereas the total amount of $\mathrm{Zn}$ in the leachates dropped by $18.5 \%$.

These results encourage us to undertake further studies in order to sequestrate toxic heavy metals from polluted waste waters and immobilize them in cements with different compositions. 


\section{Acknowledgements}

This work has been funded by the Spanish Ministry of Education and Science (MAT2007-65478) and FUNA (Fundación Universitaria de Navarra). M. Lasheras would like to thank the Friends of the University of Navarra, Inc. for funding support and Dr. Heras (Complutense University, Madrid) for valuable help in the characterisation of the polymer.

Authors are grateful to Benjamin Bessard of the IUTA de Lille (France) for his technical work.

\section{References}

[1] M.A. Janusa, C.A. Champagne, J.C. Fanguy, G.E. Heard, P.L. Laine, A.A. Landry, Solidification/stabilization of lead with the aid of bagasse as an additive to Portland cement, Microchem J. 65 (2000) 255-259.

[2] C.Y. Yin, H.B. Mahmudb, M. G. Shaaban, Stabilization/Solidification of LeadContaminated Soil Using Cement and Rice Husk Ash, J. Hazard. Mater. 137 (2006) 1758-1764.

[3] Q.Y. Chen, C.D. Hills, M. Tyrer, I. Slipper, H.G. Shen, A. Brough, Characterisation of products of tricalcium silicate hydration in the presence of heavy metals, J. Hazard. Mater. 147 (2007) 817-825.

[4] L. Zampori, I. Natali Sora, R. Pelosato, G. Dotelli, P.G. Gallo Stampino, Chemistry of cement hydration in polymer-modified pastes containing lead compounds, J. Eur. Ceram. Soc. 26 (2006) 809-816.

[5] L. Zhang, L. J.J. Catalan, A. C. Larsen, S. D. Kinrade, Effects of sucrose and sorbitol on cement-based stabilization/solidification of toxic metal waste, J. Hazard. Mater. 151 (2008) 490-498.

[6] M. Lasheras-Zubiate, I. Navarro-Blasco, J.M. Fernández, J.I. Álvarez, Studies on chitosan as an admixture for cement-based materials: assessment of its viscosity enhancing effect and complexing ability for heavy metals, J. Appl. Polym. Sci., in press, (2010) (doi: 10.1002/app33048).

[7] G. Laforest, J. Duchesne, Stabilization of electric arc furnance dust by the use of cementitious materials: Ionic competition and long-term stability, Cem. Concr. Res. 36 (2006) 1628-1634.

[8] S. Peysson, J. Péra, M. Chabannet, Immobilization of heavy metals by calcium sulfoaluminate cement, Cem. Concr. Res. 35 (2005) 2261-2270. 
[9] O. Yamaguchi, M. Ida, Y. Uchiyama, S. Hanehara, A method for the determination of total Cr(VI) in cement, J. Eur. Ceram. Soc. 26 (2006) 785-790.

[10] A. Izaguirre, J. Lanas, J.I. Alvarez, Effect of water-repellent admixtures on the behaviour of aerial lime-based mortars, Cem. Concr. Res. 39 (2009) 1095-1104.

[11] G.A.F. Roberts, J.G. Domszy, Evaluation of the viscosimetric constants of chitosan, Int. J. Biol. Macromol. 4 (1982) 374-377.

[12] R.A.A. Muzzarelli, Determination of the degree of acetylation of chitosans by first derivative ultraviolet spectrophotometry, Carbohydr. Polym. 5 (1985) 461-472.

[13] D.A. Silva, R.C.M. de Paula, J.P.A. Feitosa, A.C.F. de Brito, J.S. Maciel, H.C.B. Paula, Carboxymethylation of cashew tree exudate polysaccharide, Carbohydr. Polym. 58 (2004) 163-171.

[14] Z. Zhao, Z. Wang, N. Ye, S. Wang, A novel N,O-carboxymethyl amphoteric chitosan/poly(ethersulfone) composite MF membrane and its charged characteristics, Desalinisation 144 (2002) 35-39.

[15] F.R. Abreu, S.P. Campana-Filho, Characteristics and properties of carboxymethylchitosan, Carbohydr. Polym. 75 (2009) 214-221.

[16] EN-1015-3, Methods of test mortar for masonry. Part 3: Determination of consistence of fresh mortar (by flow table), (2000).

[17] UNE 83-816-93, Test methods. Mortars. Fresh mortars. Determination of water retentivity, (1993).

[18] EN-1015-9, Methods of test mortar for masonry. Part 9: Determination of workable life and correction time of fresh mortar, (2000).

[19] D.F. Zhang, B.Z. Ju, S.F. Zhang, L. He, \& J.Z. Yang, The study on the dispersing mechanism of starch sulfonate as a water-reducing agent for cement, Carbohydr. Polym. 70 (2007) 363-368.

[20] D.F. Zhang, B.Z. Ju, S.F. Zhang, J.Z. Yang, The study on the synthesis and action mechanism of starch succinate half ester as water-reducing agent with super retarding performance, Carbohydr. Polym. 71 (2007) 80-84.

[21] A. Izaguirre, J. Lanas, J.I. Alvarez, Behaviour of a starch as a viscosity modifier for aerial lime-based mortars, Carbohydr. Polym. 80 (2010) 222-228.

[22] EN-1015-2, Methods of test for mortar for masonry - Bulk sampling of mortars and preparation of test mortars (1999). 
[23] EA NEN 7375, Leaching characteristics of moulded or monolithic building and waste materials. Determination of leaching of inorganic components with the diffusion test (2004).

[24] C. Geffroy, A. Foissy, J.Persello, B.Cabane, Surface complexation of calcite by carboxylates in water, J. Colloid Interface Sci. 211 (1999) 45-53.

[25] Y.F. Houst, P. Bowen, F. Perche, A. Kauppi, P. Borget, L. Galmiche, J.F. Le Meins, F. Lafuma, R.J. Flatt, I. Schober, P.F.G. Banfill, D.S. Swift, B.O. Myrvold, B.G. Petersen, K. Reknes, Design and function of novel superplasticizers for more durable high performance concrete (superplast project), Cem. Concr. Res. 38 (2008) 1197-1209.

[26] D.L. Cocke, M.Y.A. Mollah, J.R. Parga, T.R. Hess, J.D. Ortego, An XPS and SEM/EDS characterization of leaching effects on lead- and zinc-doped portland cement J. Hazard. Mater. 30 (1992) 83-95.

[27] A. Zingg, F. Winnefeld, L. Holzer, J. Pakusch, S. Becker, L. Gauckler, Adsorption of polyelectrolytes and its influence on the rheology, zeta potential, and microstructure of various cement and hydrate phases, J. Colloid Interface Sci. 323 (2008) 301-312.

[28] P.Swift, H.Kinoshita, N.Collier, Phosphate-modified calcium aluminate cement for radioactive waste encapsulation, in: L.M. Grover, M.P. Hofmann, H. Rossetto, A.M. Smith (Eds.), 30 ${ }^{\text {th }}$ Cement and Concrete Science Conference, Birmingham, 2010, pp. 135-138.

[29] E. Guibal, Interactions of metal ions with chitosan-based sorbents: a review, Sep. Purif. Technol. 38 (2004) 43-74.

[30] M. Rhazi, J. Desbrières, A. Tolaimate, M. Rinaudo, P. Vottero, A. Alalgui, Contribution to the study of the complexation of copper by chitosans and oligomers, Polymer 43 (2002) 1267-1276.

[31] M.A.C. Gollmann, M.M. da Silva, A.B. Masuero, J.H.Z. dos Santos, Stabilization and solidification of $\mathrm{Pb}$ in cement matrices, J. Hazard. Mater. 179 (2010) 507514

[32] Dutch Soil Quality Regulation, 10 October 2006

[33] H.A. van der Sloot, Comparison of the characteristic leaching behavior of cements using standard (EN 196-1) cement mortar and an assessment of their long-term environmental behavior in construction products during service life and recycling, Cem. Concr. Res. 30(2000) 1079-1096. 
[34] M. Yousuf, A. Mollah, R. K. Vempati, T.C. Lin, D. L. Cocke, The interfacial chemistry of solidification/stabilization of metals in cement and pozzolanic material systems, Waste Manage. 15 (1995) 137-148. 
Table 1. Experimental parameters for $\mathrm{Zn}$ and $\mathrm{Pb}$ quantification by electrothermal atomic absorption spectrometry.

\begin{tabular}{lcc}
\hline & Instrumental parameters & \\
\hline & $\mathbf{Z n}$ & $\mathbf{P b}$ \\
Wavelength $(\mathrm{nm})$ & 213.9 & 283.3 \\
Slit width $(\mathrm{nm})$ & 0.7 & 0.7 \\
Lamp current $(\mathrm{mA})$ & 4 & 10 \\
Sample - modif. vol. $(\mu \mathrm{L})$ & $15-5$ & $15-5$ \\
Measurement mode & Peak area & Peak area \\
Source lamp & Hollow cathode & Hollow cathode \\
Background correction & Zeeman & Zeeman \\
\hline
\end{tabular}

Temperature programs

\begin{tabular}{lccccccccc}
\hline Step & \multicolumn{2}{c}{ Temperature $\left({ }^{\circ} \mathrm{C}\right)$} & \multicolumn{2}{l}{ Ramp (s) } & \multicolumn{4}{c}{ Hold (s) } & \multicolumn{2}{c}{$\operatorname{Argon}\left(\mathrm{mL} \mathrm{min}^{-1}\right)$} & Read on \\
& $\mathbf{Z n}$ & $\mathbf{P b}$ & $\mathbf{Z n}$ & $\mathbf{P b}$ & $\mathbf{Z n}$ & $\mathbf{P b}$ & $\mathbf{Z n}$ & $\mathbf{P b}$ & \\
Drying & 130 & 130 & 15 & 20 & 40 & 50 & 250 & 250 & - \\
Charring & 600 & 850 & 15 & 20 & 35 & 35 & 250 & 250 & - \\
Atomization & 1700 & 1600 & 0 & 0 & 5 & 5 & 250 & 0 & Yes \\
Cleaning & 2400 & 2500 & 1 & 2 & 3 & 5 & 250 & 250 & - \\
\hline
\end{tabular}




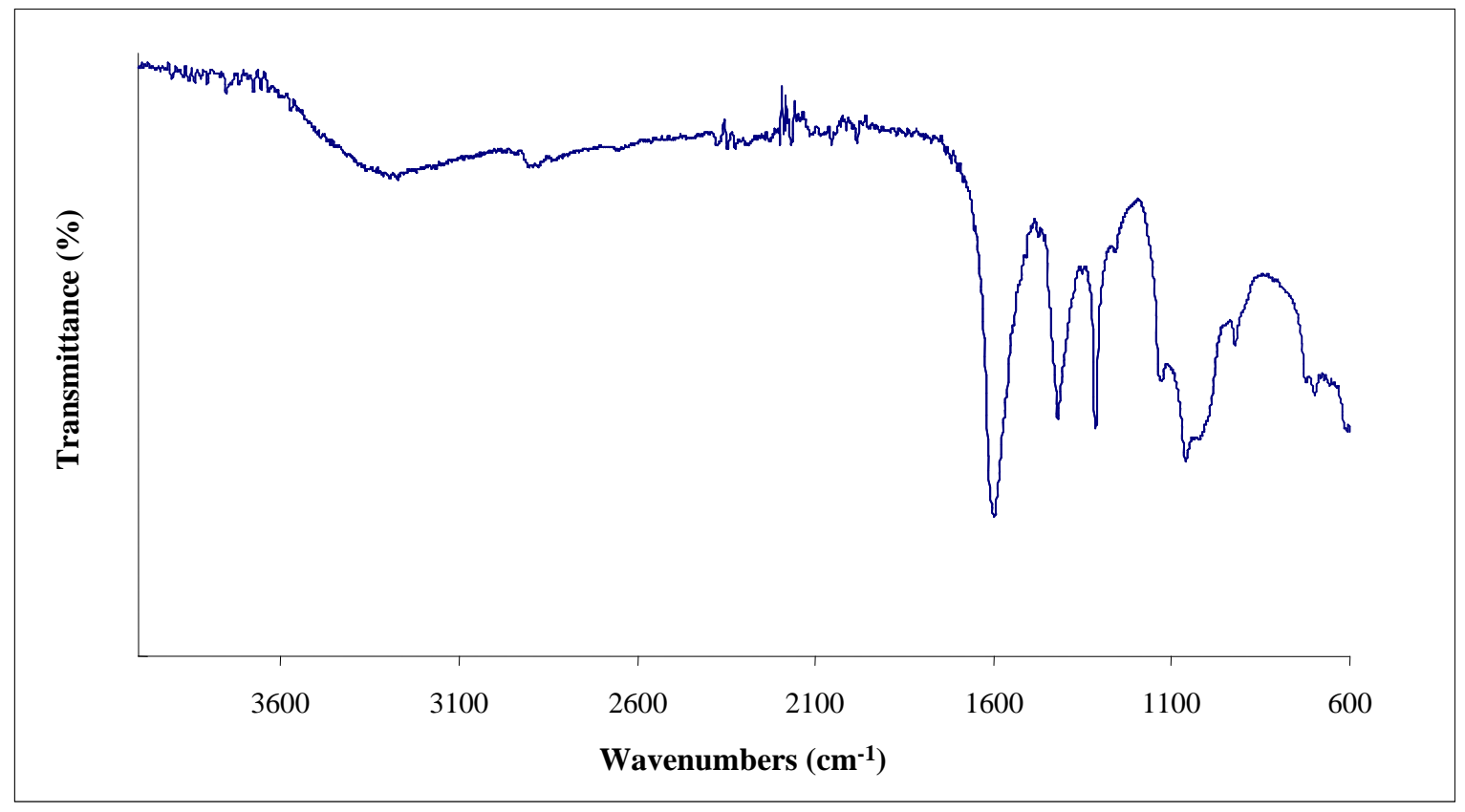

Fig. 1. FTIR spectrum of the assayed carboxymethylchitosan $(\mathrm{CMCH})$. 


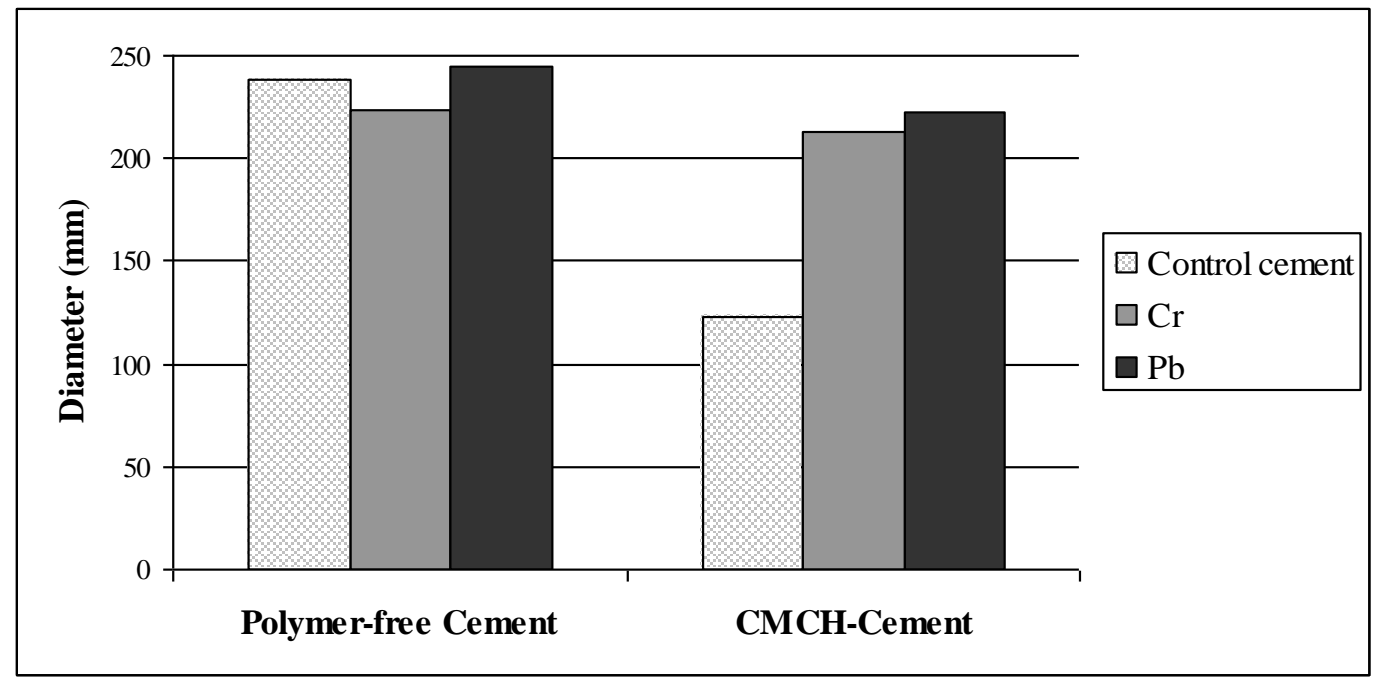

Fig. 2. Effect of the addition of different heavy metals on the consistency - slump values - of polymer-free and CMCH-modified fresh cement mortars. 


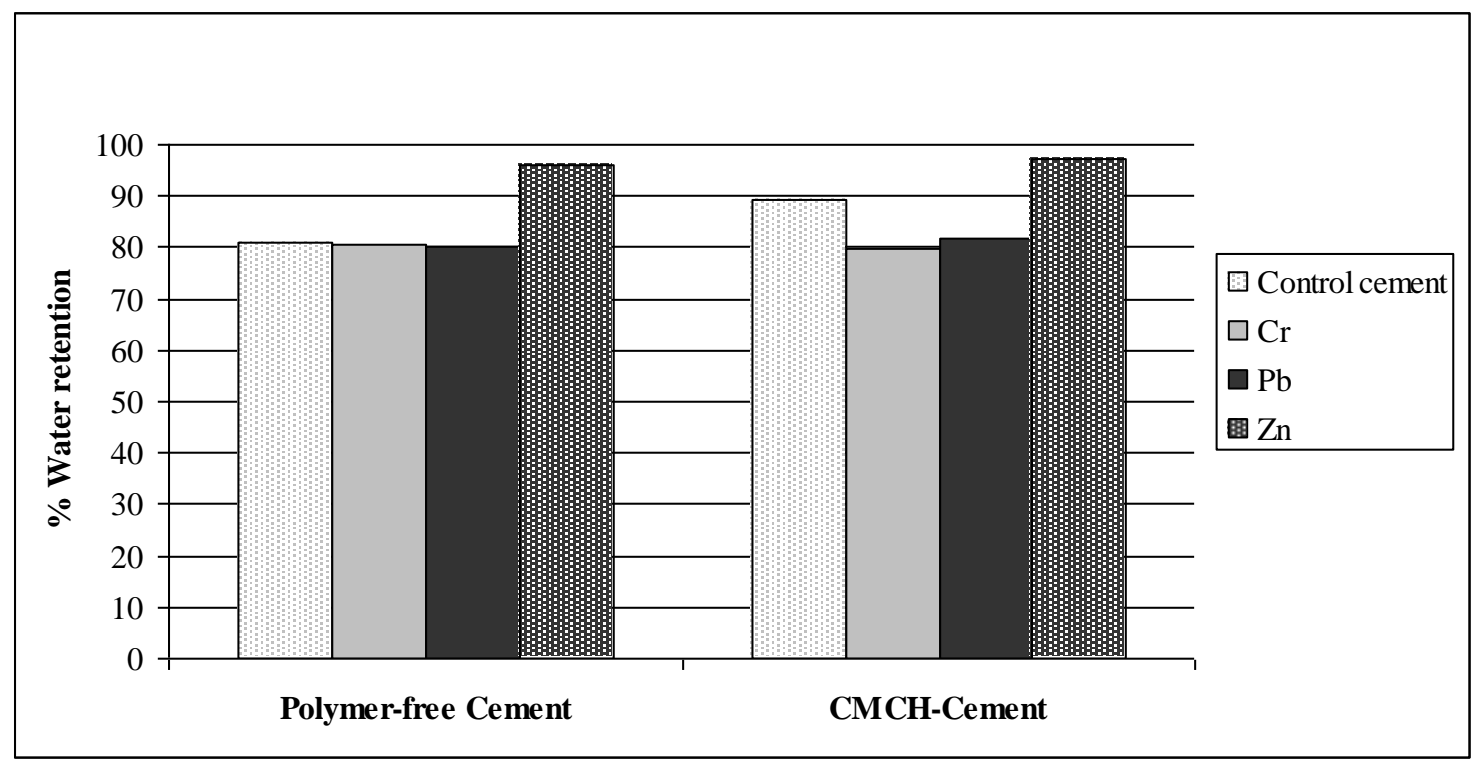

Fig. 3. Effect of the addition of different heavy metals on the water retention ability of polymer-free and $\mathrm{CMCH}$-modified fresh cement mortars. 


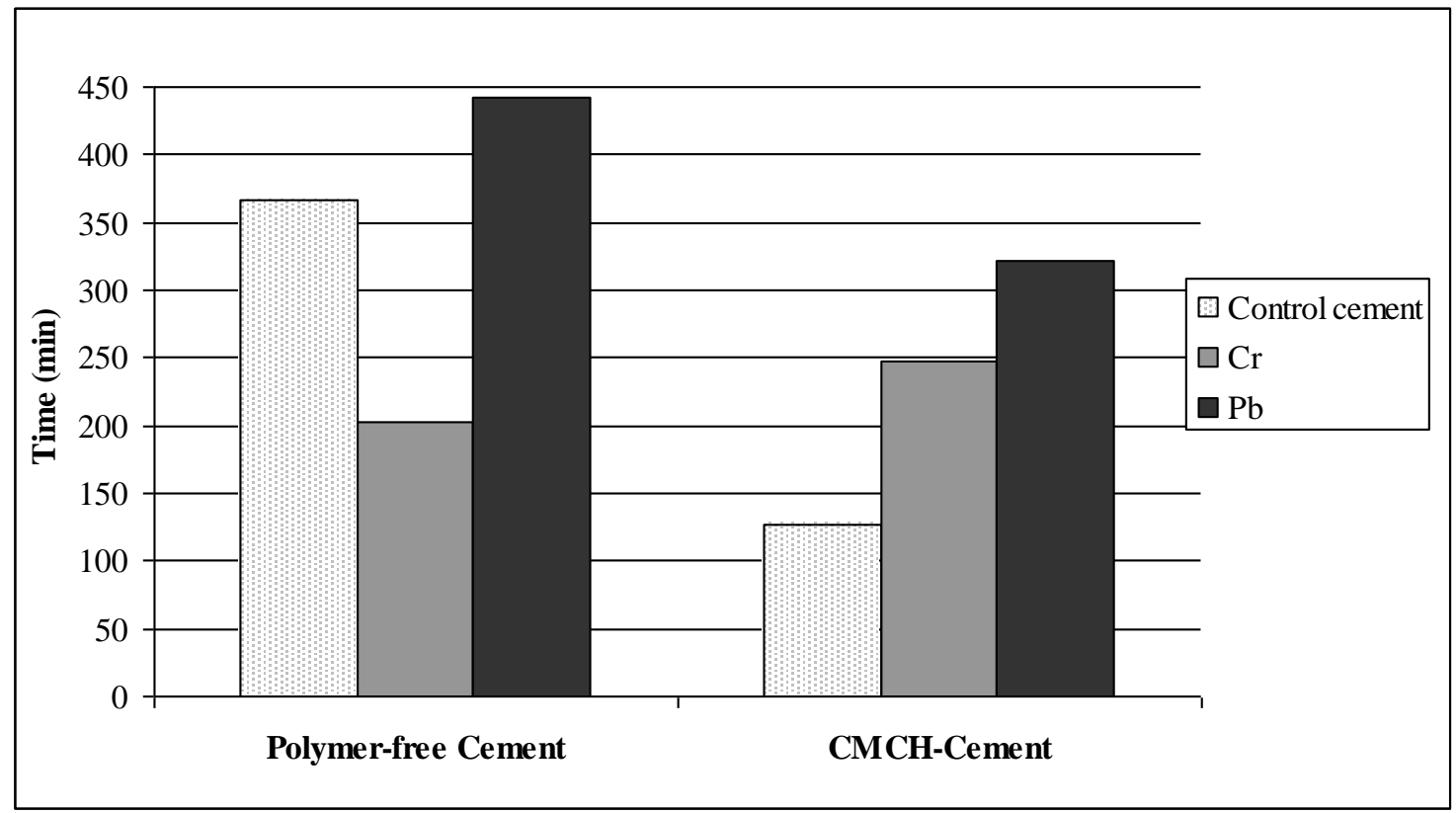

Fig. 4. Influence of the heavy metal addition on the setting time of polymer-free and $\mathrm{CMCH}$-modified fresh cement mortars. 


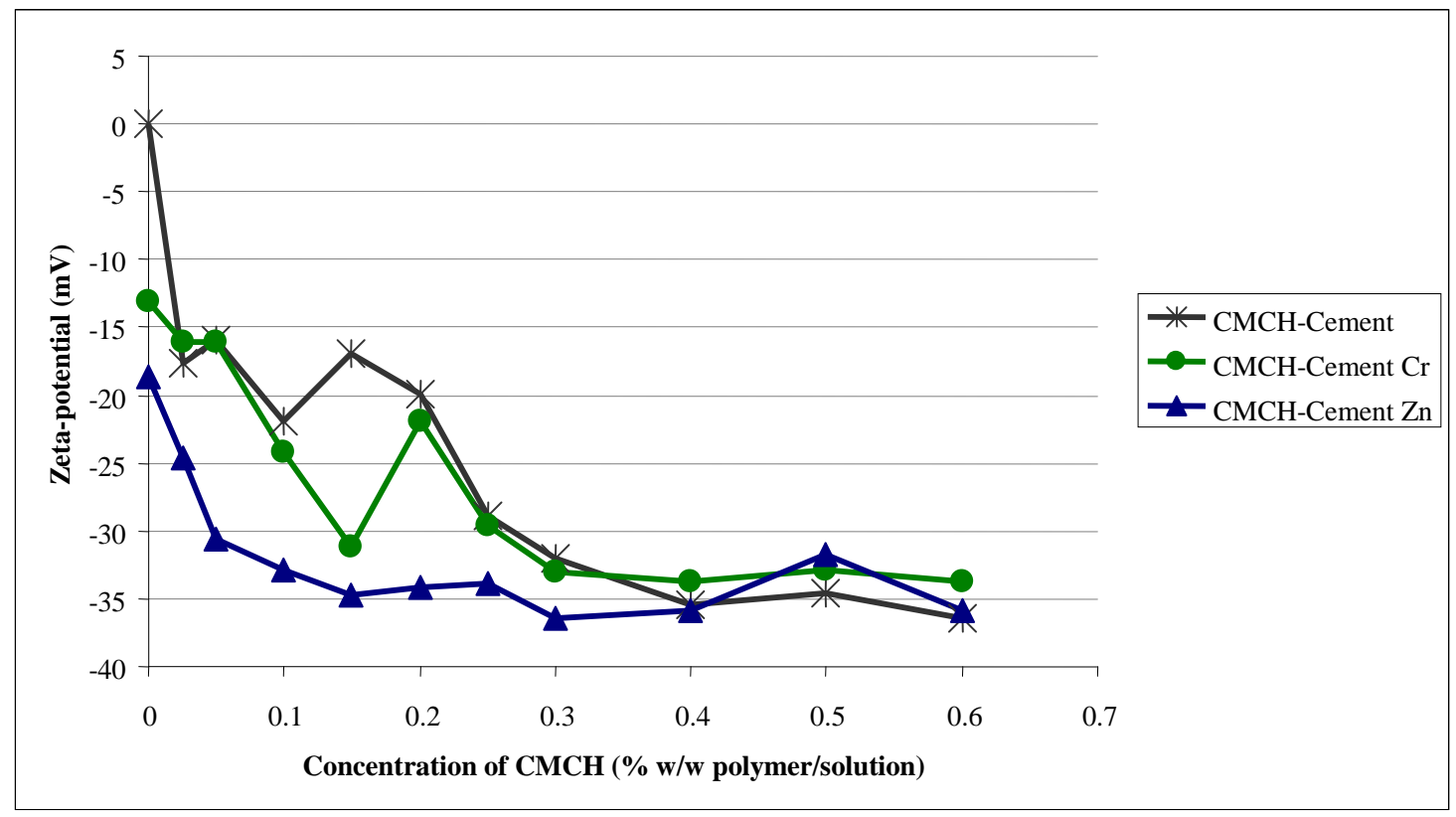

Fig. 5. Influence of heavy metals on the zeta potential trend for the metal-free cement solution, $1 \%$ wt. $\mathrm{Cr} /$ cement solution and $1 \% \mathrm{wt}$. $\mathrm{Zn} /$ cement solution, under increasing $\mathrm{CMCH}$ concentrations. 


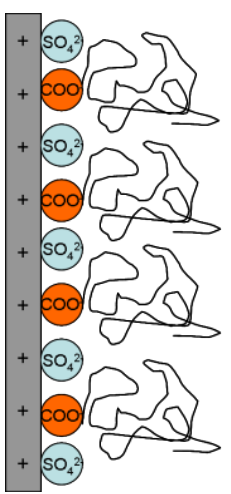

(a)

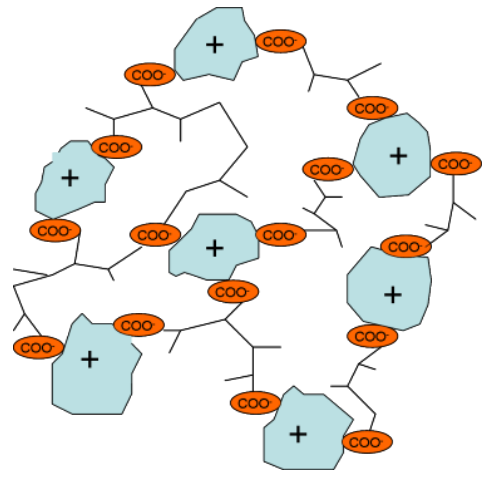

(b)

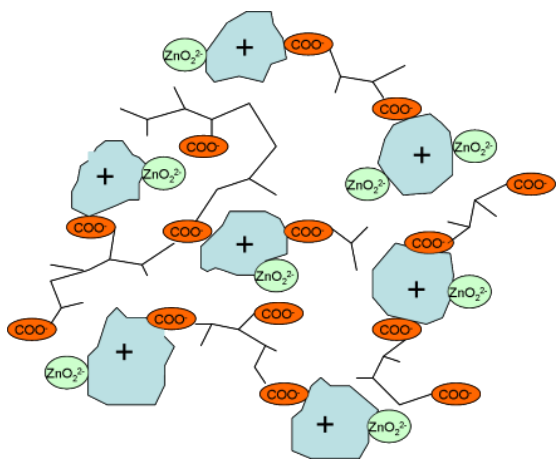

(c)

Fig. 6. Schematic representation of (a) the adsorption of $\mathrm{CMCH}$ to the positively charged surface of the cement particles; (b) interlinking of cement particles with $\mathrm{CMCH}$; and (c) example of a competitive adsorption of the negatively charged oxoanions (e.g. zincates in this case). 

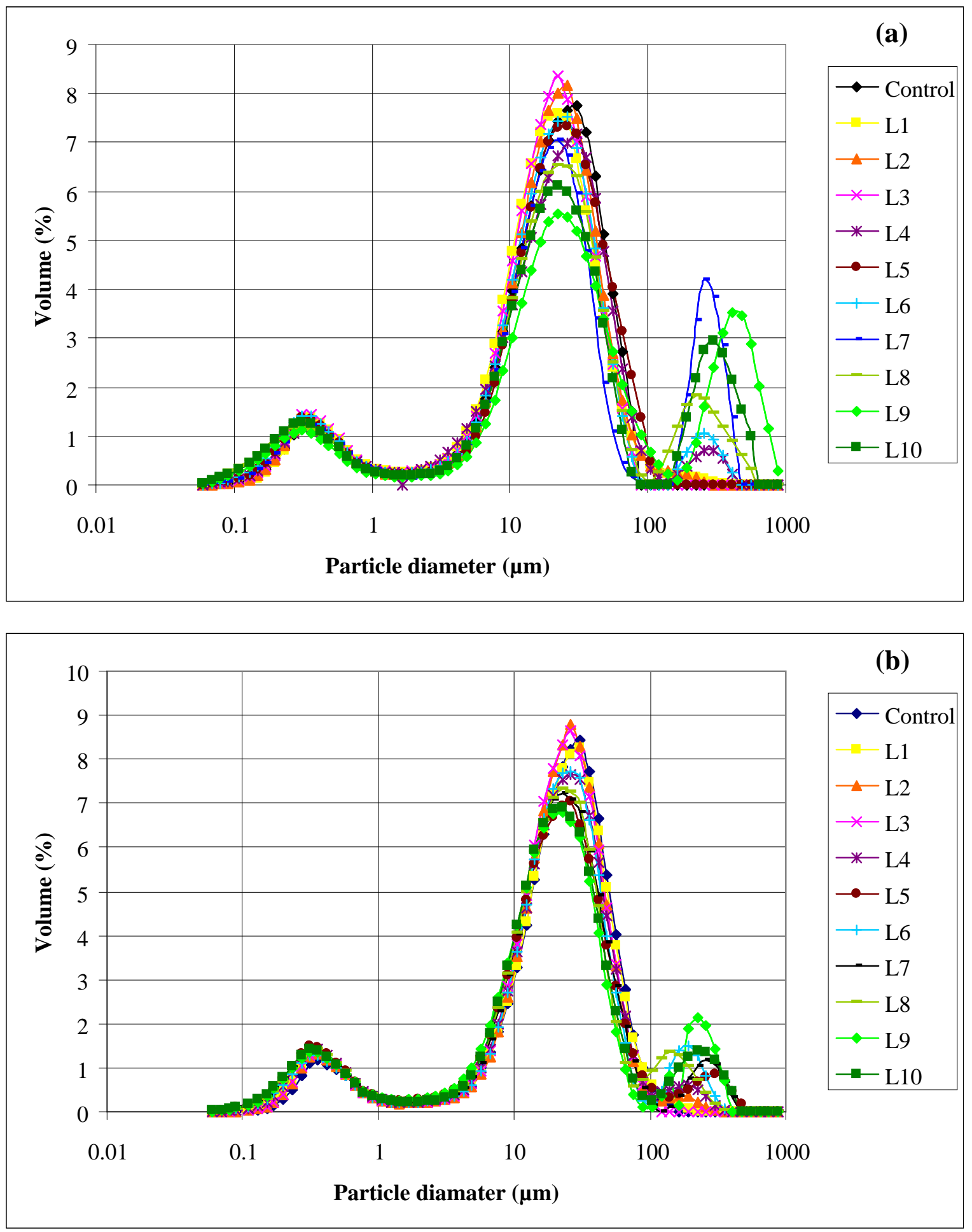

Fig. 7. Effect of the heavy metal presence on the particle size distribution in cement solutions for increasing $\mathrm{CMCH}$ concentrations (Control: $0 \% \mathrm{CMCH}$; 1 to L10: $0.1 \%$ to $1.0 \% \mathrm{CMCH}$ ). (a) metal-free cement solution; (b) 1 wt. \% Pb-bearing cement solution. 

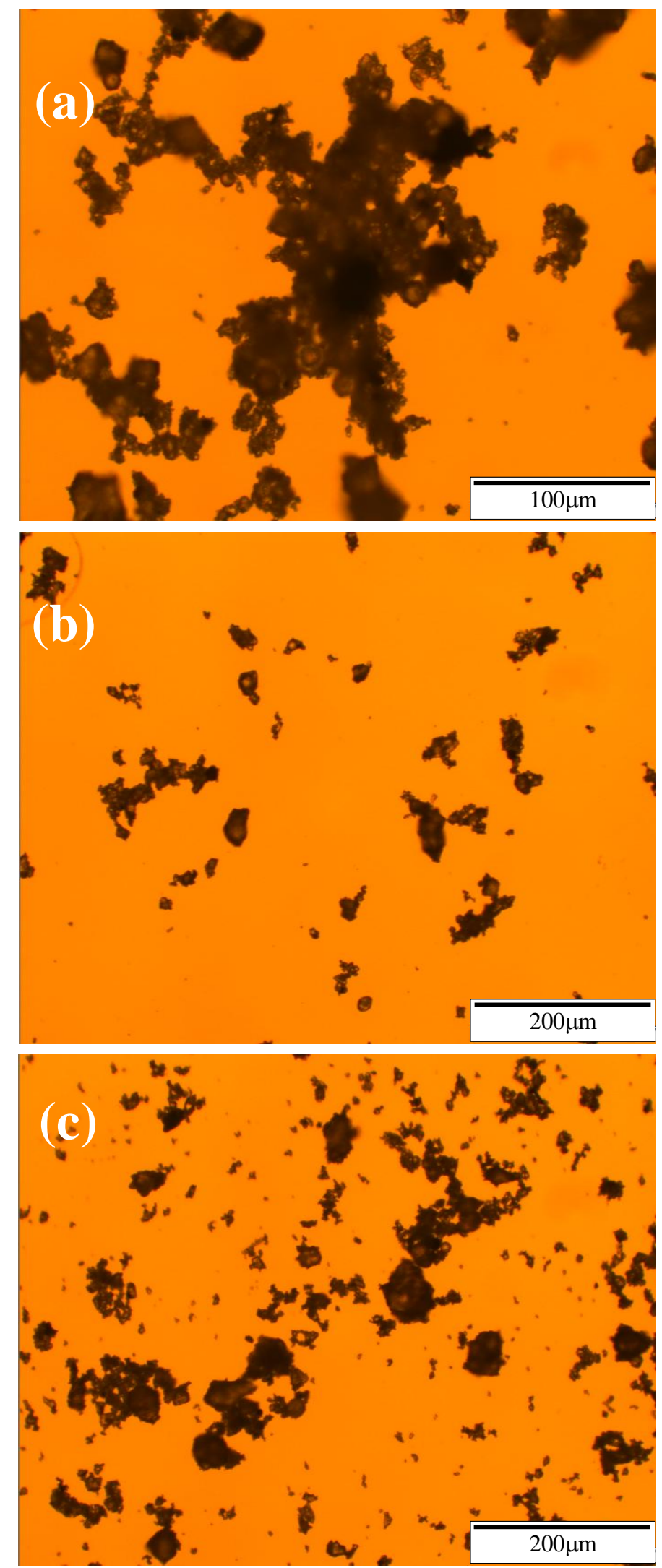

Fig. 8. Images of a) metal-free b) Cr-bearing and c) Pb-bearing $\mathrm{CMCH}$-cement solutions. 


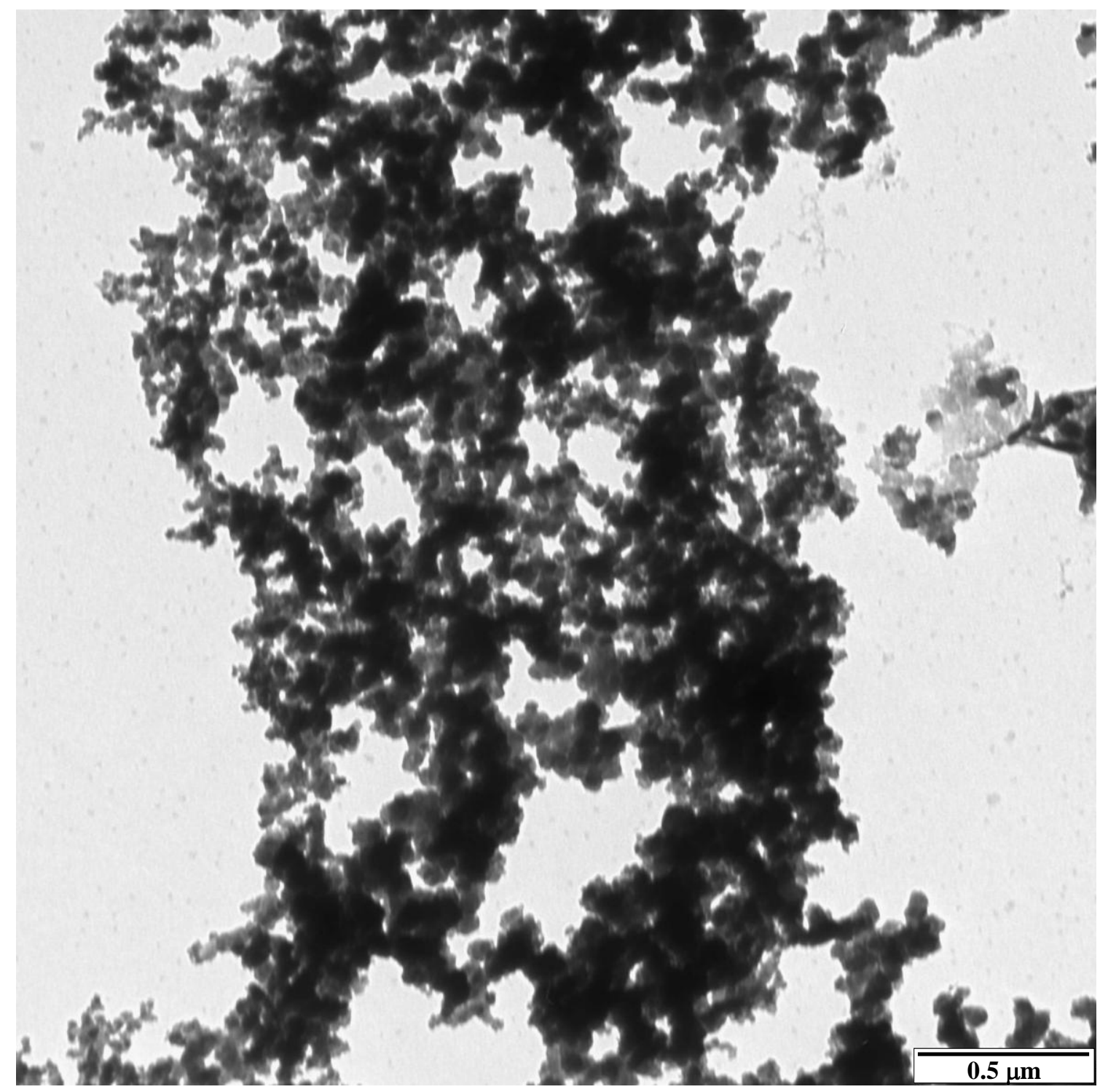

Fig. 9. TEM micrograph of a cement particle agglomerate in the presence of $\mathrm{CMCH}$. 


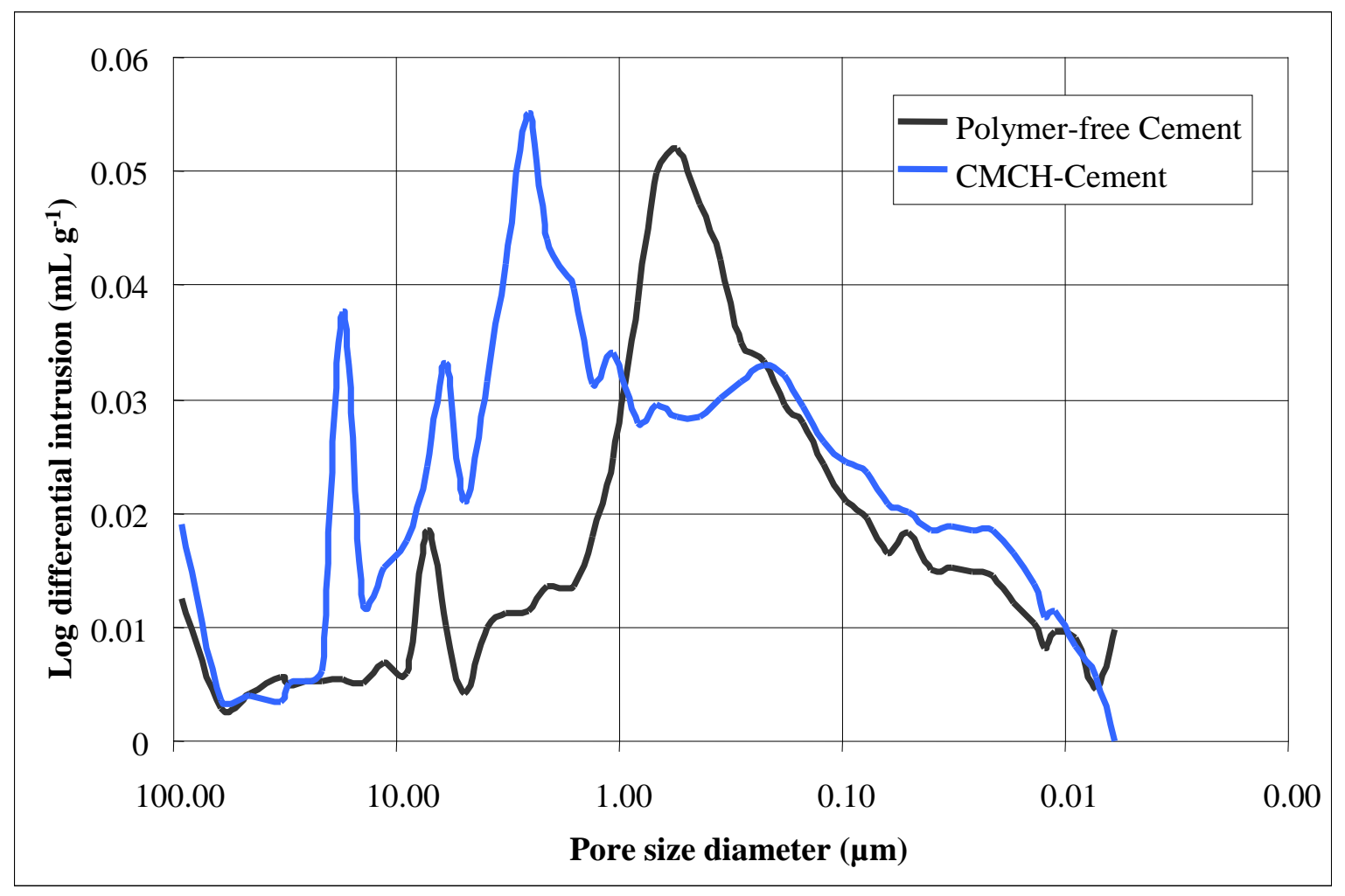

Fig. 10. Pore size distribution of polymer-free and $\mathrm{CMCH}$-modified 28-day hardened mortars. 

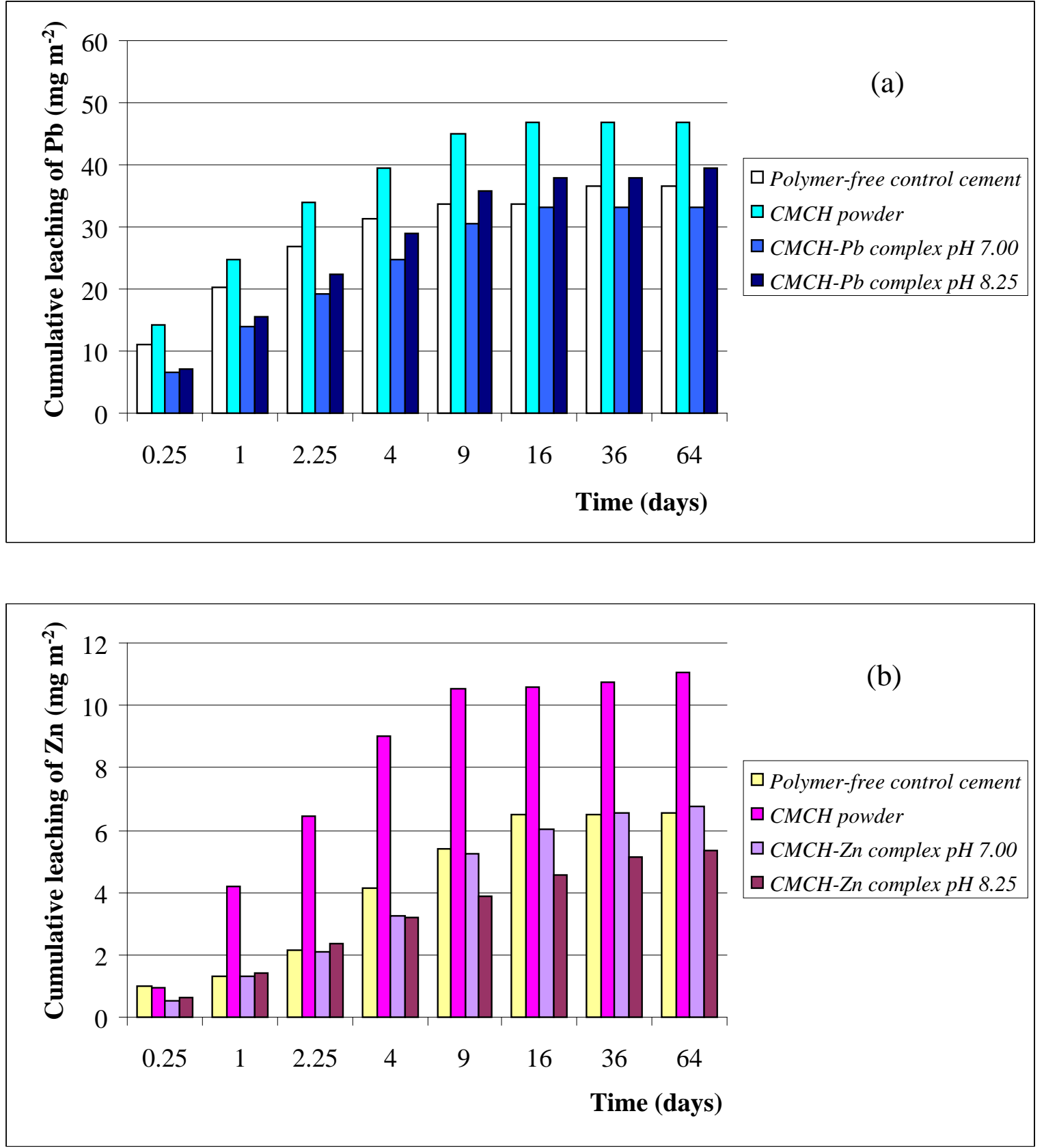

Fig. 11. Accumulated leachability results for (a) $\mathrm{Pb}$ and (b) $\mathrm{Zn}$, in: polymer-free cement mortars; mortars modified by the addition of powdered $\mathrm{CMCH}$; and mortars with metals and $\mathrm{CMCH}$ incorporated as a previously formed complex at either $\mathrm{pH} 7.00$ or $\mathrm{pH} 8.25$. 